OPEN ACCESS

Edited by:

Yinduo Ji,

University of Minnesota Twin Cities,

United States

Reviewed by:

Yoann Le Breton,

University of Maryland, College Park,

United States

Junji Xing,

Houston Methodist Research Institute,

United States

*Correspondence:

Lin Wei

weilin501@163.com

tThese authors have contributed equally to this work.

Received: 26 January 2018 Accepted: 13 April 2018

Published: 11 May 2018

Citation:

Ma C, Gao X, Wu S, Zhang L, Wang J, Zhang Z, Yao Z, Song $X$, Li W, Wang $X$, Feng $H$ and Wei $L$

(2018) M Protein of Group a Streptococcus Plays an Essential Role in Inducing High Expression of A2O in

Macrophages Resulting in the

Downregulation of Inflammatory

Response in Lung Tissue.

Front. Cell. Infect. Microbiol. 8:131.

doi: 10.3389/fcimb.2018.00131

\section{Protein of Group a Streptococcus Plays an Essential Role in Inducing High Expression of A20 in Macrophages Resulting in the Downregulation of Inflammatory Response in Lung Tissue}

Cuiqing $\mathrm{Ma}^{1+}$, Xue Gao ${ }^{1 \dagger}$, Shuhui Wu ${ }^{2 \dagger}$, Ling Zhang ${ }^{1}$, Jiachao Wang ${ }^{1}$, Zhengzheng Zhang ${ }^{1}$, Zhiyan Yao ${ }^{1}$, Xiaotian Song ${ }^{1}$, Wenjian Li $^{1}$, Xiurong Wang ${ }^{1}$, Huidong Feng ${ }^{1}$ and Lin Wei ${ }^{1 *}$

\begin{abstract}
${ }^{1}$ Key Laboratory of Immune Mechanism and Intervention on Serious Disease in Hebei Province, Department of Immunology, Basic Medical College, Hebei Medical University, Shijiazhuang, China, ${ }^{2}$ Department of Microbiology and Immunology, Hebei University of Chinese Medicine, Shijiazhuang, China
\end{abstract}

Group A streptococcus (GAS), a common pathogen, is able to escape host immune attack and thus survive for longer periods of time. One of the mechanisms used by GAS is the upregulated expression of immunosuppressive molecules, which leads to a reduction in the production of inflammatory cytokines in immune cells. In the present study, we found that macrophages produced lower levels of proinflammatory cytokines (IL-1 $\beta$, TNF- $\alpha$, IL-6) when challenged with GAS than they did when challenged with Escherichia coli (E. coli). Simultaneously, in a mouse model of lung infection, GAS appeared to induce a weaker inflammatory response compared to $E$. coli. Our data also indicated that the expression of the A20 transcriptional regulator was higher in GAS-infected macrophages than that in macrophages infected with $E$. coli, and that high expression of A20 correlated with a reduction in the production of TRAF6. SiRNA targeting of A2O led to the increased production of TRAF6, IL-1 $\beta$, TNF- $\alpha$, and IL-6, suggesting that A20 inhibits synthesis of these key proinflammatory cytokines. We also investigated the pathway underlying A20 production and found that the synthesis of A20 depends on My88, and to a lower extent on TNFR1. Finally, we showed a significant reduction in the expression of A20 in macrophages stimulated by M protein-mutant GAS, however, a speB-GAS mutant, which is unable to degrade $M$ protein, induced a greater level of A20 production than wild type GAS. Collectively, our data suggested that M protein of GAS was responsible for inducing A20 expression in macrophages, which in turn down-regulates the inflammatory cytokine response in order to facilitate GAS in evading immune surveillance and thus prolong survival in the host.

Keywords: Group A Streptococcus (GAS), macrophages, A20, M protein, negative regulation 


\section{INTRODUCTION}

Group A streptococcus (GAS), also referred to as Streptococcus pyogenes, is the most common and versatile of human pathogens. Furthermore, GAS is responsible for a wide spectrum of human diseases, ranging from superficial skin infections to lethal diseases (Cunningham, 2000; Bryant et al., 2003; Liang et al., 2012). In particular, GAS is known to survive for long periods in hosts and for recurrent attacks, particularly in the elderly and children. However, the strategy of how GAS is able to stay alive in hosts for long periods is not clear. Previous studies have reported that GAS exploits complement regular factors to bind surface proteins, such as M and FbaA protein (Terao et al., 2001; Pandiripally et al., 2003; Ma et al., 2011), or to promote the cleavage of cell surface-bound C3b to iC3b to inhibit opsonization by C3, which in turn promotes bacterial entry into epithelial cells and protects against antibiotics (Cue et al., 1998; Collin and Olsén, 2002; Collin et al., 2002). As the first line of defense in innate immunity, macrophages can trigger an inflammatory response following the recruitment of neutrophils and more macrophages, to eradicate invasive pathogens. However, the mechanisms underlying the way in which GAS can escape innate immunity cell attack and survive in the body are poorly defined. We speculated that GAS should have a reverse effect on macrophages and be able to inhibit their function. Our previous experiments have screened a range of negative regulatory proteins such as SOCS1, SOCS2, COCS3, and A20 in macrophages following GAS infection and found that both SOCS1 (Wu et al., 2015) and A20 were activated. However, the mechanism responsible for the inhibition of A20 is different from that of SOCS1. In the present study, we focused on the interaction between GAS and A20 in macrophages.

A20 is an important negative regulator of immune cells, and its expression can be induced by a wide variety of stimuli, including tumor necrosis factor (TNF), interleukin (IL)1, phorbol esters, hydrogen peroxide, lipopolysaccharide (LPS), viruses, and the cell surface receptor CD40. A20 can alsorestrain nuclear factor- $\mathrm{kB}$ signals mediated by Toll-like receptors, tumor necrosis factor receptor 1 (TNFR1), and NOD2 (nucleotide oligomerization domain-2)-like receptor to create feedback that inhibits the excessive release of TNF- $\alpha$, IL-1, IL- 6 , IL8 , intercellular adhesion molecules, and other proinflammatory factors. In this manner, A20 can control cell apoptosis and necrosis (Opipari et al., 1992; Wertz et al., 2004; Hitotsumatsu et al., 2008).

In this study, we found GAS induced lower levels of p65, a key transcription factor of inflammatory cytokines, and inflammatory factors in macrophages, when compared to those inducedby E. coli. In addition, A20 expression induced by GAS appeared earlier and was higher than that induced by E. coli. GAS is known to produce a variety of exocrine proteins and express a series of cell surface proteins. Therefore, we attempted to identify the probable molecular mechanisms of interaction between GAS and A20, and in particular, which major components of GAS were involved in the production of A20 by macrophages.

\section{MATERIALS AND METHODS}

\section{Mice}

Female C57BL/6 mice, aged 7-8 weeks, were purchased from Beijing Laboratory Animal Center. MyD88 ${ }^{-/-}$mice were also purchased from the Model Animal Research Center of Nanjing University. All mice were housed and manipulated in accordance with the Care and Use of Laboratory Animals (China), and were maintained under specific pathogen-free conditions. The protocol for animal experiments was approved by the animal experimental ethics committee of Hebei Medical University (Reference number: 2015046).

\section{Bacteria}

Streptococcal strain GAS SF370 M1 and other mutant GAS were stored in our laboratory at $-80^{\circ} \mathrm{Cand}$ routinely grown at $37^{\circ} \mathrm{C}$ in Todd-Hewitt Broth supplemented with $0.5 \%$ yeast extract (THY) (Difco, MI, USA). In brief, cryopreserved GAS were reanimated, inoculated into agar plates containing sheep blood, and incubated at $37^{\circ} \mathrm{C}$ for $18 \mathrm{~h}$. A single colony was then transferred to $3 \mathrm{ml}$ of THY broth at $37^{\circ} \mathrm{C}$ and shaken overnight at $250 \mathrm{rpm}$. Finally, the bacteria were collected in $1.5-\mathrm{ml}$ microcentrifuge tubes by centrifugation at $4,000 \mathrm{rpm}$ for $5 \mathrm{~min}$, washed three times, resuspended in $1 \mathrm{ml}$ phosphate-buffered saline (PBS), and counted. E. coli was routinely cultivated at $37^{\circ} \mathrm{C}$ in $\mathrm{LB}$ culture media.

\section{Cells}

The murine macrophage cell line RAW264.7 (RAW cells) was purchased from the Cell Centre of Chinese Academy of Medical Sciences and was maintained in DMEM supplemented with $100 \mathrm{U} / \mathrm{ml}$ penicillin and streptomycin, and 10\% FBS (Gibco BRL, USA) (complete medium). Mouse bone marrow-derived macrophages (BMDMs) were generated from bone marrow cells obtained from the femurs of 15-week-old wild type (WT) or

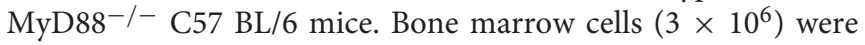
cultured with DMEM complete medium containing $10 \mathrm{ng} / \mathrm{ml} \mathrm{M-}$ CSF. After culturing for 7 days, the fully differentiated BMDMs were used for experiments.

\section{GAS Infection of Macrophages}

RAW cells or BMDMs were seeded at $1 \times 10^{6} /$ well in 6well plates containing culture medium without antibiotics. The next day, GAS and E. coli were harvested during the midlogarithmic growth phase and added to cells at a multiplicity of infection (MOI) equal to 10 . After $2 \mathrm{~h}$ of incubation at $37^{\circ} \mathrm{C}$, non-adherent extracellular bacteria were eliminated by removing the culture medium and washing using phosphate buffer saline (PBS). Adherent extracellular bacteria were subsequently killed by incubation with fresh medium containing $10 \mu \mathrm{g} / \mathrm{mL}$ penicillin $\mathrm{G} /$ streptomycin at $37^{\circ} \mathrm{C}$ for $2 \mathrm{~h}$. At specific time points after infection, supernatants were collected for ELISA, and the cells were prepared for quantitative real-time polymerase chain reaction (qPCR) or Western blot analysis. 


\section{qPCR}

Cells collected at various time points were used to isolate total RNA using the RNeasy kit (Takara, Bio. Inc., Japan) in accordance with the manufacturer's protocol. qPCR analysis was then performed using oligo (dT) and random primers by a modified protocol. In brief, cDNA samples converted from $1 \mu \mathrm{g}$ total RNA was diluted at several concentrations. Diluted cDNA was mixed with a pair of primers $(10 \mu \mathrm{M})$ targeting mouse IL$1 \beta$, IL- 6 , TNF- $\alpha$, and $\beta$-actin cDNA sequences at an annealing temperature of $60^{\circ} \mathrm{C}$ and with 35 amplification cycles following the manufacturer's instructions. The following primers were used for PCR amplification: IL-6-F: AAG GAG TGG CTA AGG ACC
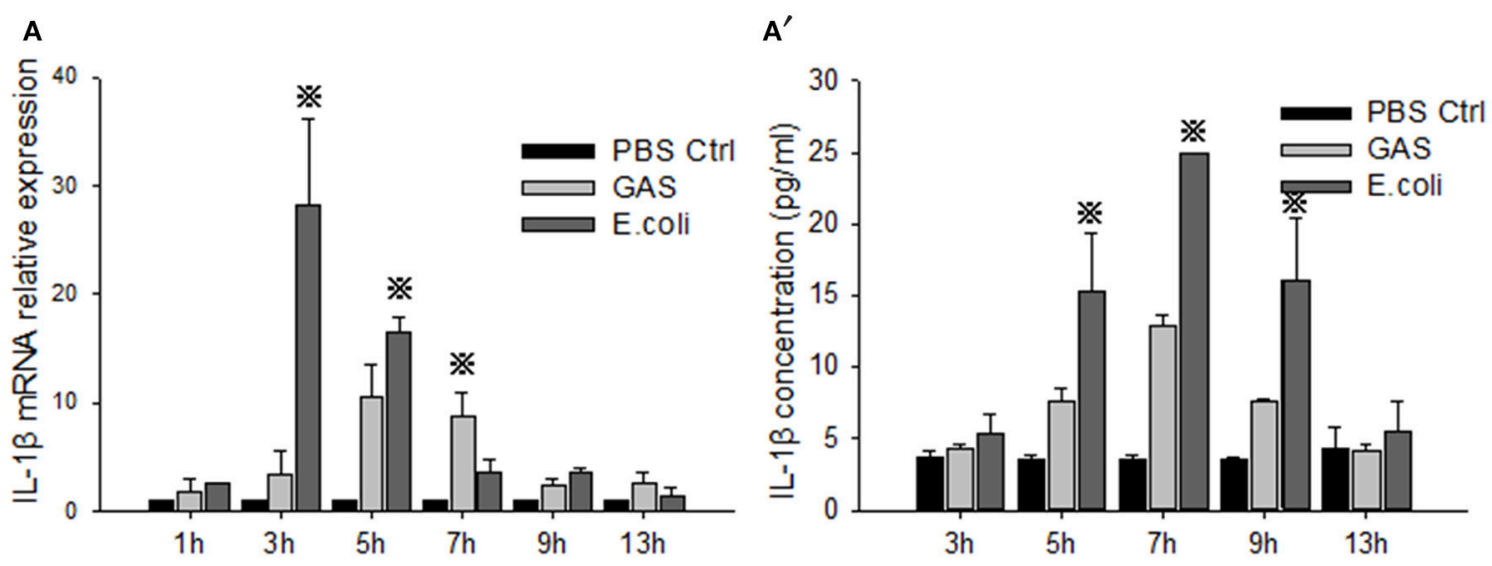

B

$\mathbf{B}^{\prime}$
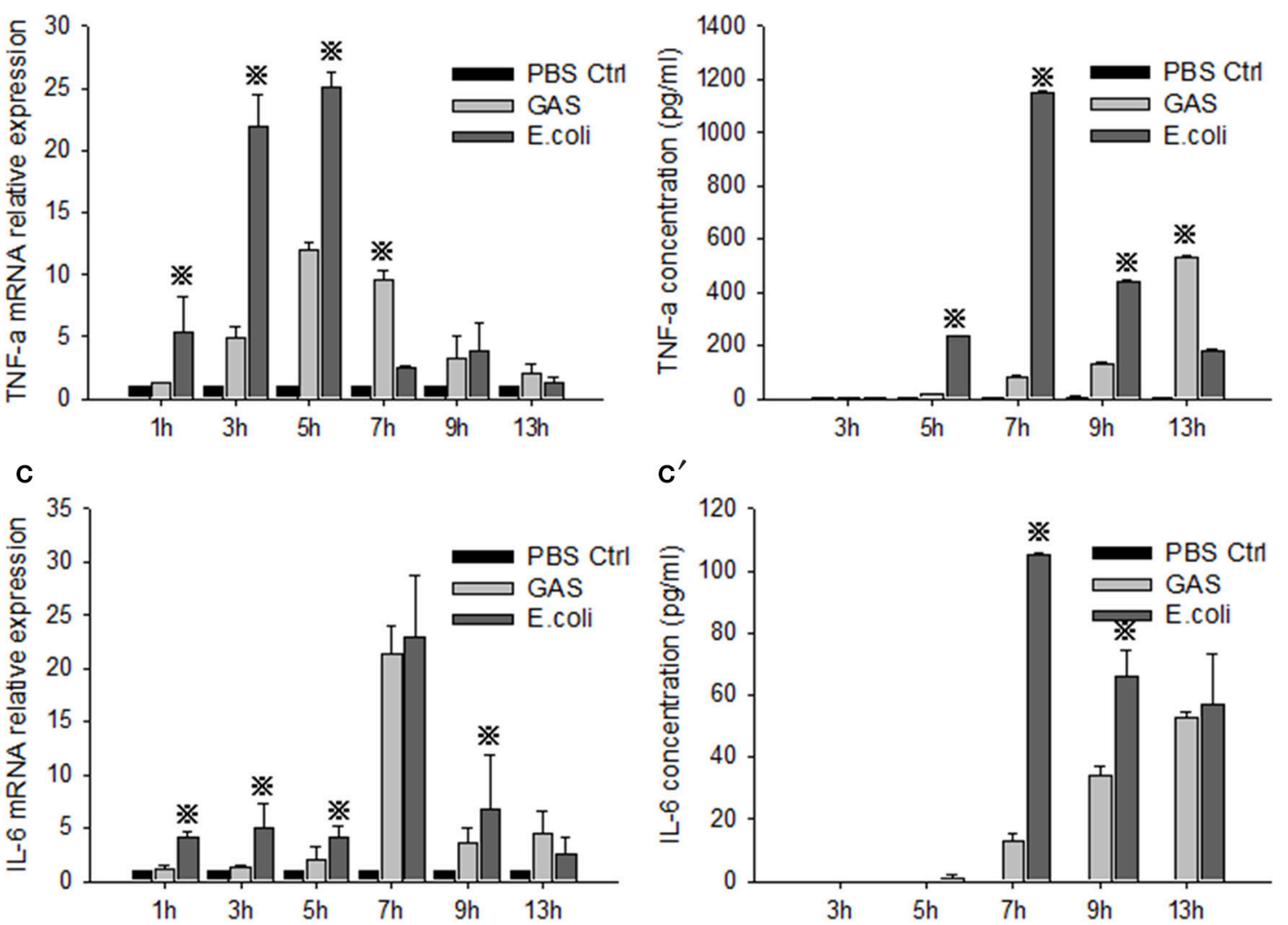

FIGURE 1 | Evaluation of proinflammatory cytokines in RAW cells stimulated with GAS or E. coli. RAW264.7 cells were seeded at a concentration of $1 \times 10^{6} /$ well in a 6-well plate containing medium without antibiotics overnight and then infected with GAS, or E. coli as a control, at an MOI of 10. We then collected supernatant and cells from each group at different time points. Total RNA was isolated from cells using RNeasy, and QPCR analysis was performed to detect the mRNA level of IL-1 $\beta$

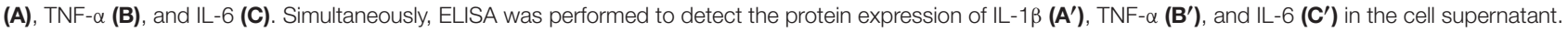
Each experiment was performed at least three times. Results are presented as mean \pm SD. $P<0.05$ vs. E. coli group. 
A

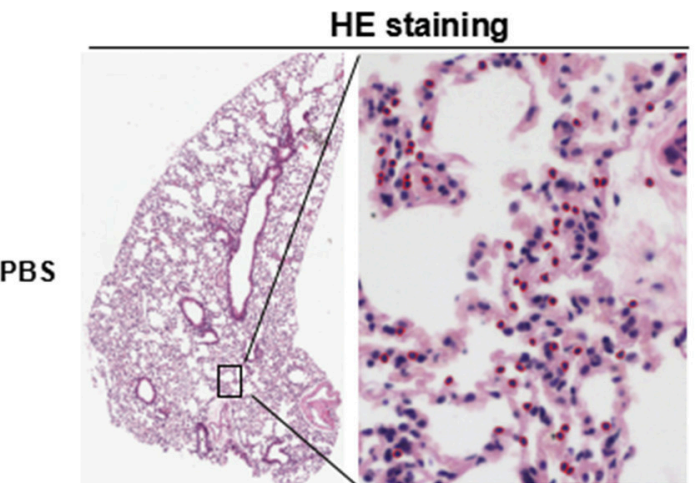

GAS
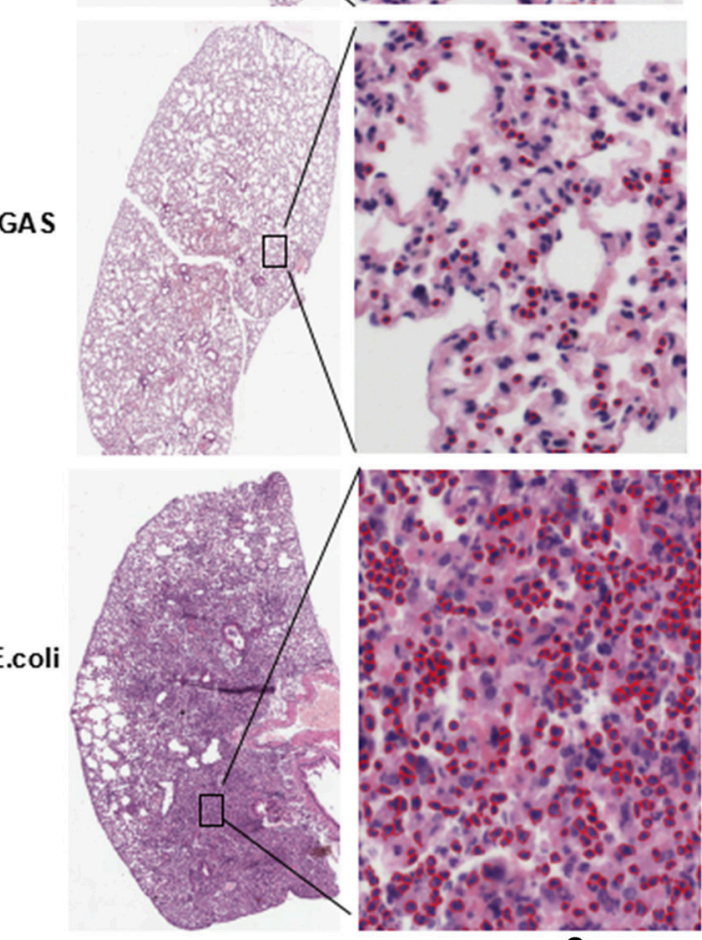

B

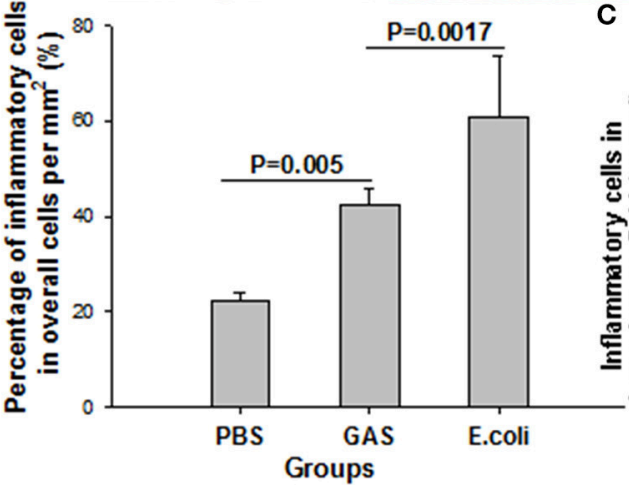

PAS staining
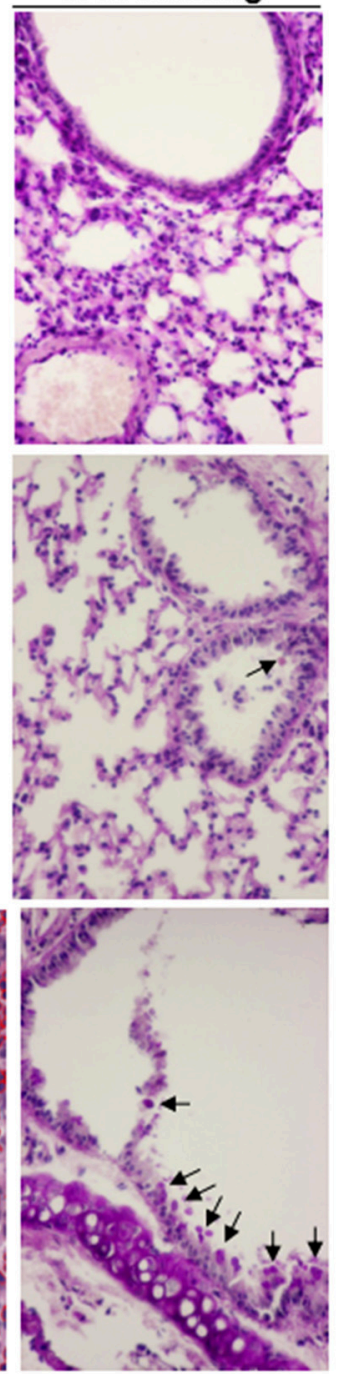

$P<0.0001$

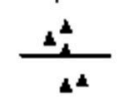

$\mathbf{P}=\mathbf{0 . 0 0 0 4}$

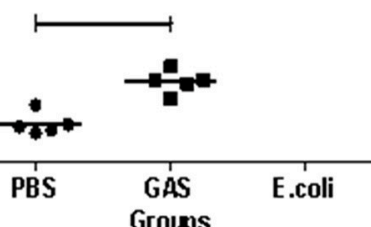

FIGURE 2 | Histological evaluation of inflammatory response in mouse lung tissue following GAS or E. coli infection. The three experimental groups of mice were separately prepared for histopathological analysis. (A) Representative views of lung sections treated with PBS, GAS, or E. coli. In the left panels, H\&E staining shows the overall outline of lung slices, with a magnified image. Inflammatory cells are identified by red circles in the middle panels (H\&E staining, $\times 10$ and $\times 40)$. Periodic acid-Schiff (PAS) staining showed bronchiolar mucus production in each group (right panels, objective $\times 20$ ). (B) Quantitative analysis of recruited inflammatory cells per square $\mathrm{mm}$. (C) Inflammatory cells were counted in lung lavage fluid (per $\mathrm{mll}$ ). Each experiment was repeated three times, and similar results were obtained on each occasion. 
AA; IL-6-R: GTT TGC CGA GTA GAT CTC AAA; IL-1 $\beta$-F: TTC CTT GTG CAA GTG TCT GAA G; IL- $1 \beta-R$ : CAC TGT CAA AAG GTG GCA TTT; TNF- $\alpha-F$ : TGA CGT GGA ACT GGC AGA AGA; TNF- $\alpha$-R: TGG GCC ATA GAA CTG ATG AGA G; $\beta$-actin-F: TAC CCA GGC ATT GCT GAC AGG; $\beta$-actin-R: ACT TGC GGT GCA CGA TGG A. The $2-\Delta \Delta$ Ct method of relative quantification was used to calculate changes in the expression of target genes (Kubista et al., 2006). Data are presented as the mean \pm standard deviation of triplicate samples and are representative of three independent experiments.

\section{ELISA}

Supernatants from RAW cells were harvested at different points after GAS stimulation and stored at $-70^{\circ} \mathrm{C}$, and then enzymelinked immunosorbent assay (ELISA, eBioscience Inc. USA) was performed to measure the expression of IL-6, TNF- $\alpha$, or IL- $1 \beta$, in accordance with the manufacturer's instructions. In brief, $50 \mu \mathrm{l}$ of each sample, and $50 \mu \mathrm{l}$ of sample diluents, were added into pre-washed wells and a standard dilution was added to all standard wells. Subsequently, $50 \mu \mathrm{l}$ biotinconjugate was added to all wells followed by incubation at room temperature for $2 \mathrm{~h}$. After washing, streptavidin-HRP and then TMB substrate solution were successively added to each well. The absorbance of each well was then read at a wave length of $450 \mathrm{~nm}$. Data are presented as the mean \pm standard deviation of triplicate samples and are representative of three independent experiments.

\section{Histology}

C57BL/6 mice were anesthetized with $1 \%$ pentobarbital sodium, and challenged by intranasal (i.n.) instillation of $10^{8} \mathrm{CFU}$ $50 \%$ tissue culture infective doses (TCID50)/50 $\mu$ l of GAS or E. coli, with PBS acting as a negative control. After $48 \mathrm{~h}$, the treated mice were sacrificed and the right lung was isolated and immediately fixed in $4 \%$ paraformaldehyde. The left lung was perfused with $1 \mathrm{ml}$ PBS to collect bronchoalveolar lavage fluid (BALF), which was centrifuged. Most of the supernatant was removed and cell smears of centrifugal sedimentation were stained with Wright Giemsa. The number of leukocytes present was then counted under oil microscopy. Tissue samples were subsequently processed, embedded in paraffin, thin sectioned, and placed on slides coated with L-lysine. Sections were stained with hematoxylin and eosin (H\&E) and periodic acid Schiff (PAS) to demonstrate the inflammatory response.

\section{Western Blotting}

Total cell protein was extracted from cells infected by GAS or E. coli using the RIPA protein extraction kit (Beyotime, CHN) and was then used for Western blotting to calculate the changes in A20, TRAF6, and p-P65. In brief, cells infected by GAS or E. coli were washed twice, mixed with RIPA lysis buffer, and then centrifuged at $8,000 \mathrm{~g}$ for $5 \mathrm{~min}$ at $4^{\circ} \mathrm{C}$. Then, the supernatant was collected and protein concentration was determined according to the Bradford method (Bradford, 1976). Total cell lysates or $M$ protein were then separated using sodium dodecyl sulfate polyacrylamide gel electropheresis (SDS-PAGE) and transferred to polyvinylidene difluoride (PVDF) membrane. After blocking, blots were incubated with rabbit monoclonal antibodies against A20/TNFAIP3 (Cell signaling Inc.), TRAF6 (Cell signaling Inc. USA), and p-NF-кB p65 (Cell signaling Inc. USA); $\beta$-actin (Cell signaling Inc.) was used as an internal control. Finally, blots were hybridized with horseradish-peroxidase-(HRP-)-conjugated goat anti-rabbit immunoglobulin G (IgG), incubated with enhanced chemiluminescence (ECL) solution (PerkinElmer Life Sciences, USA), and finally exposed to X-ray film.

\section{A RAW 264.7}

E.coli

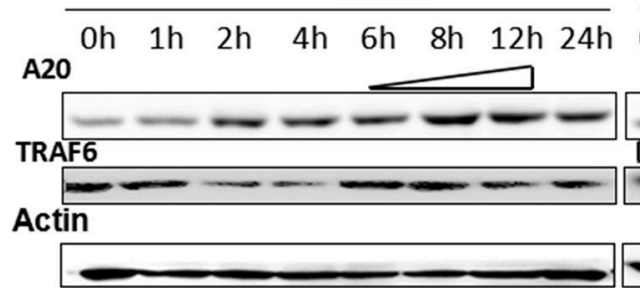

B BMDM

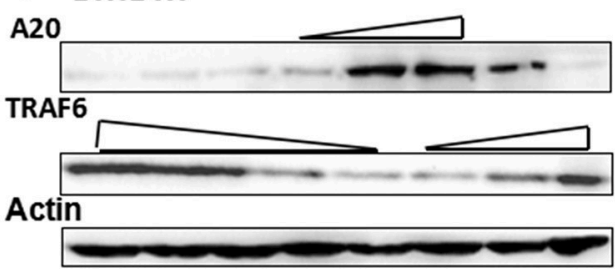

GAS
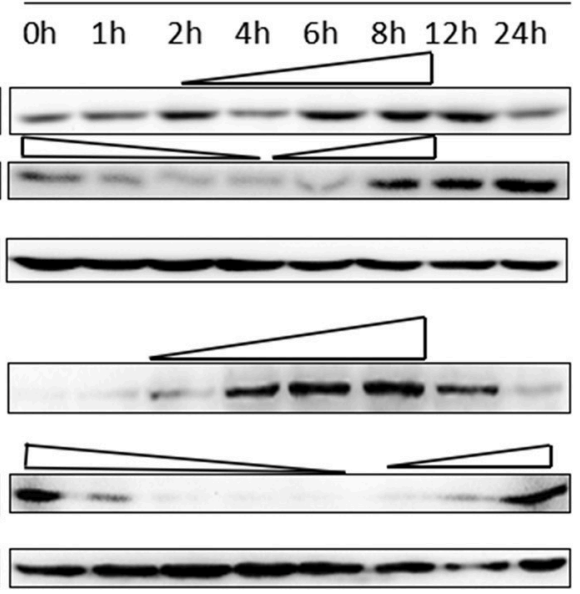

FIGURE 3 | Expression of A20 and its target protein, TRAF6, in GAS-induced macrophages. Macrophages from wild-type mice were infected with GAS or E. coli at an $\mathrm{MOI}$ of 10. At different post-infection times, the protein levels of A20 and TRAF6 were detected by Western blot in RAW 264.7 cells (A) or BMDMs (B). Each experiment was repeated three times, and similar results were obtained on each occasion. 


\section{SiRNA}

For SiRNA treatment, $2 \times 10^{5}$ RAW264.7 cells were seeded per well on a six-well tissue culture plate for $18 \mathrm{~h}$ at $37^{\circ} \mathrm{C}$ in a $\mathrm{CO}_{2}$ incubator. SiA20 transfection medium was then added to the prewashed cells in accordance with a siRNA transfection protocol (Santa Cruz Biotechnology, Inc. USA) and then incubated for $6 \mathrm{~h}$ at $37^{\circ} \mathrm{C}$ in a $\mathrm{CO}_{2}$ incubator. After the transfection mixture was removed, the cells were stimulated with heat-killed GAS for $7 \mathrm{~h}$, and live GAS for $1 \mathrm{~h}$, respectively. Finally, the supernatant of the transfected cells was collected for ELISA. Cells were washed once with PBS, and then fixed with $4 \%$ paraformaldehyde for immunoflurescence studies, or harvested for Western blot analysis or qRT-PCR analysis.

\section{Immunoflurescence}

Cells were grown on glass cover slips and incubated overnight at $37^{\circ} \mathrm{C}$ and $5 \% \mathrm{CO}_{2}$ in an incubator. After being washed four times, cells were fixed in $4 \%$ paraformaldehyde and blocked in $1 \%$ BSA (Saint Louis, USA) for $1 \mathrm{~h}$ at $37^{\circ} \mathrm{C}$.
Subsequently, cells were incubated with monoclonal anti-pP65 (1: 100) and anti-A20 (1:100) antibodies overnight at $4^{\circ} \mathrm{C}$. After four rinses, FITC-conjugated and secondary antibodies were used to visualize the target proteins by fluorescence microscopy (Tokyo, Japan). Nuclei were counter-stained with DAPI.

\section{Statistical Analysis}

SPSS statistical software (version 21.0) was used for data analysis. The standard deviation (SD) of the mean is shown unless otherwise indicated. Statistical significance is indicated as either ${ }^{*} p<0.05$ or ${ }^{* *} p<0.01$.

\section{RESULTS}

\section{Gas Induced a Weaker Inflammatory Reaction Than E. coli}

RAW cells were stimulated by GAS or E. coli, respectively, and the proinflammatory cytokines IL-1 $\beta$, TNF- $\alpha$, and IL-6,

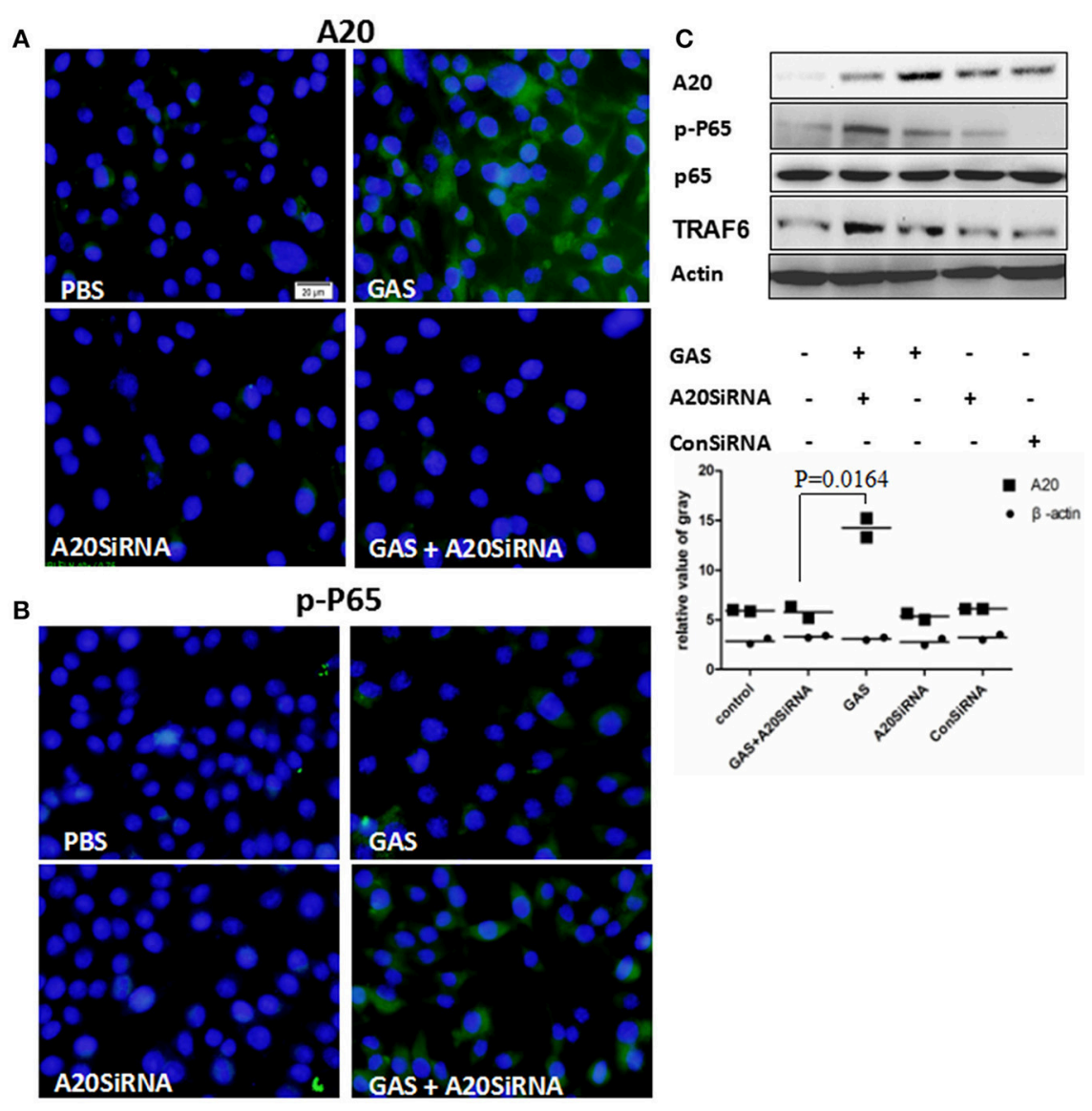

FIGURE 4 | Expression of A20 and the phosphorylation of p65 in RAW 264.7 macrophages with and without A20 SiRNA following GAS infection. RAW 264.7 cells were incubated with A20 SiRNA for $30 \mathrm{~min}$, and then infected with GAS at an MOI of 10: 1. Six hours post-infection, an immunofluorescence assay (magnification, 3100) was performed to detect the expression of A20 (Green) (A) and p-P65 (Green) (B), which was verified by Western blotting (C). qPCR (for mRNA expression) or ELISA (for protein expression) were also used to detect the levels of proinflammatory cytokines in RAW cells or in the supernatant (Figure 5). The blue color represents DAPI staining. Representative cells from the same field for each group are shown. Each experiment was repeated three times, and similar results were obtained on each occasion. 
were detected by qRT-PCR and ELISA at different time points. The relative mRNA expression levels of IL- $1 \beta$, TNF$\alpha$, and IL-6 in GAS-infected RAW cells were all weaker than those in $E$. coli-infected RAW cells at 1,3 , and $5 \mathrm{~h}$ post-stimulation $(P<0.05)$ (Figures $1 \mathrm{~A}-\mathrm{C})$. Accordingly, the protein levels of these proinflammatory cytokines were also lower than those produced by $E$. coli-infected RAW cells until
$9 \mathrm{~h}$ post-stimulation $(P<0.05)$ (Figures $\left.1 \mathbf{A}^{\prime}-\mathbf{C}^{\prime}\right)$, suggesting that GAS induced a lower level of proinflammatory cytokine reaction in RAW cells than $E$. coli at an early stage after infection.

It was not clear whether these lower levels of proinflammatory cytokines would induce a weaker state of inflammation in response to GAS compared with E. coli. We therefore tested
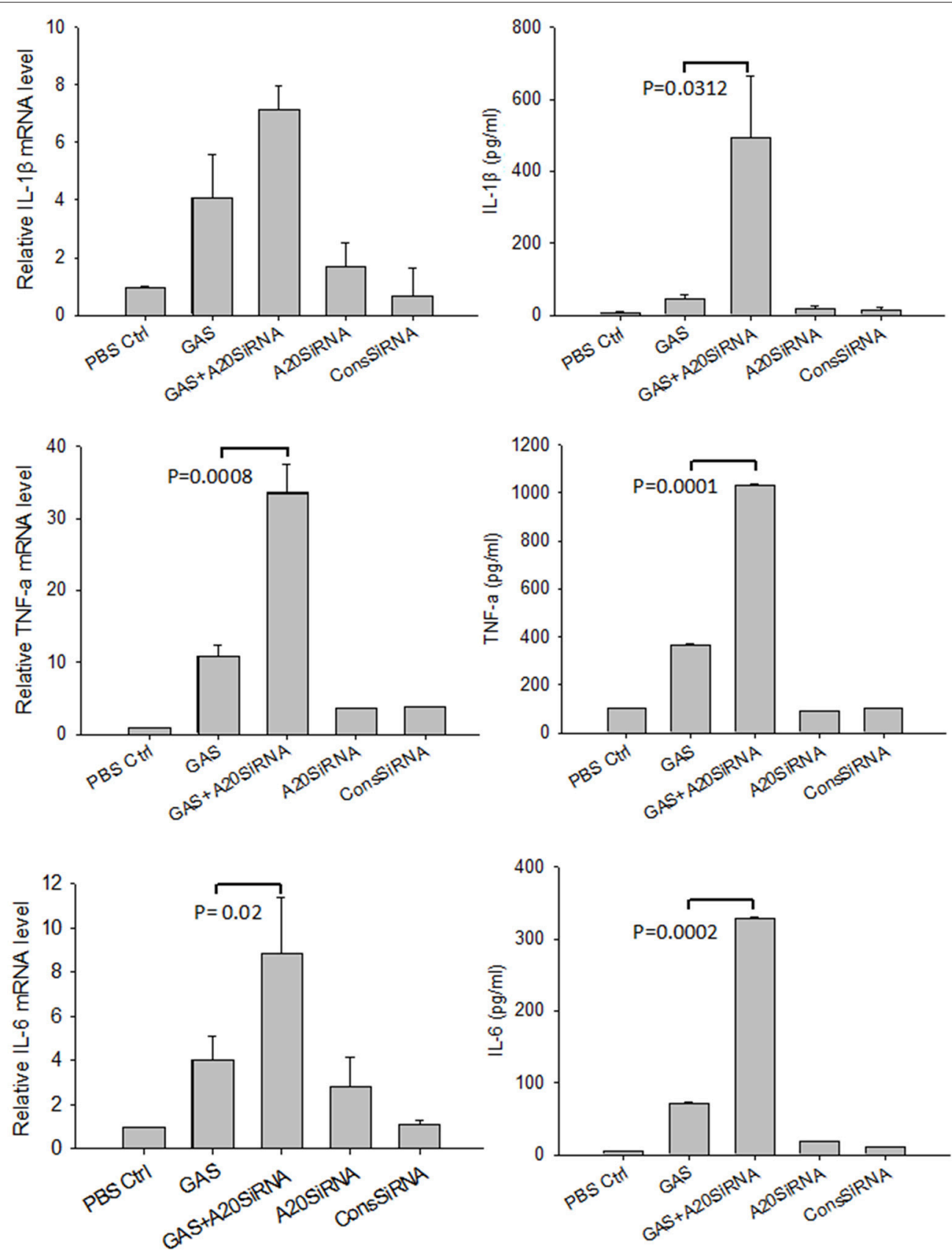

FIGURE 5 | Expression of proinflammatory cytokines in RAW 264.7 macrophages with and without A20 SiRNA following GAS infection. RAW 264.7 cells were incubated with A20 SiRNA for $30 \mathrm{~min}$, and then infected with GAS at an MOI of 10. And $6 \mathrm{~h}$ post-infection, ELISA and RT-PCR were performed to analyze the expression of proinflammatory cytokines. Each experiment was repeated three times, and similar results were obtained on each occasion. Results are presented as mean \pm SD. 
A

A20

p-P65

p65

Actin

E.coli

GAS

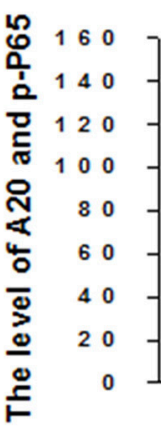

B

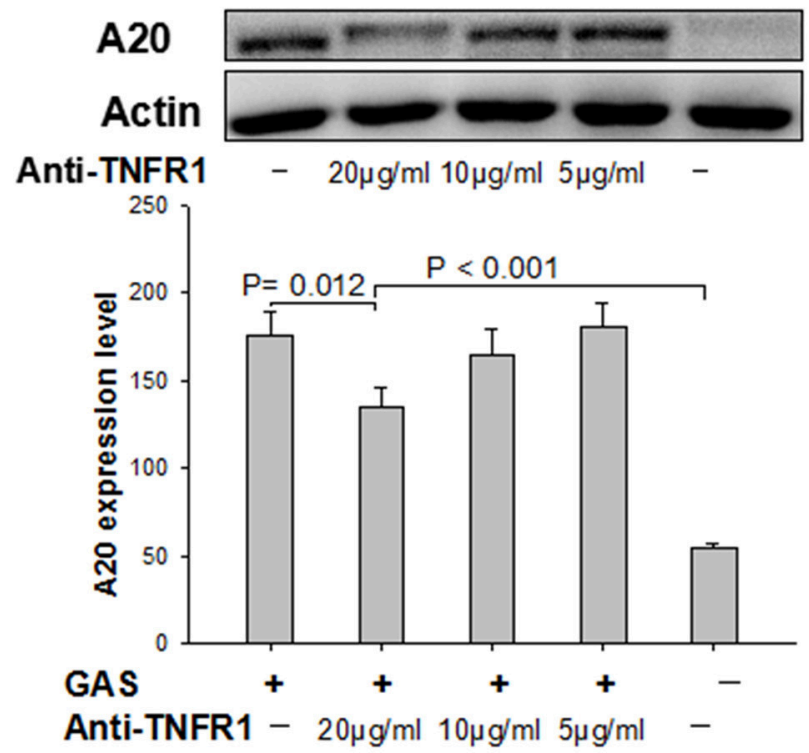

Anti-TNFR1 - $20 \mu \mathrm{g} / \mathrm{ml} 10 \mu \mathrm{g} / \mathrm{ml} 5 \mu \mathrm{g} / \mathrm{ml}$
MYD88\%-
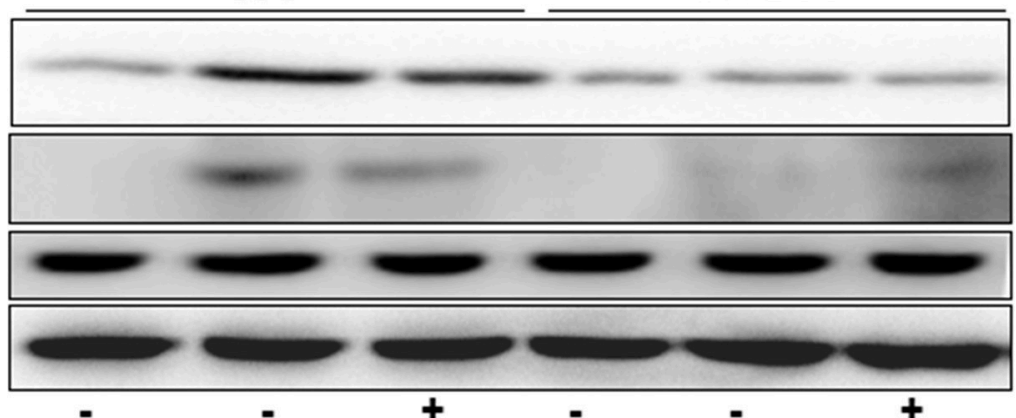

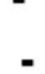
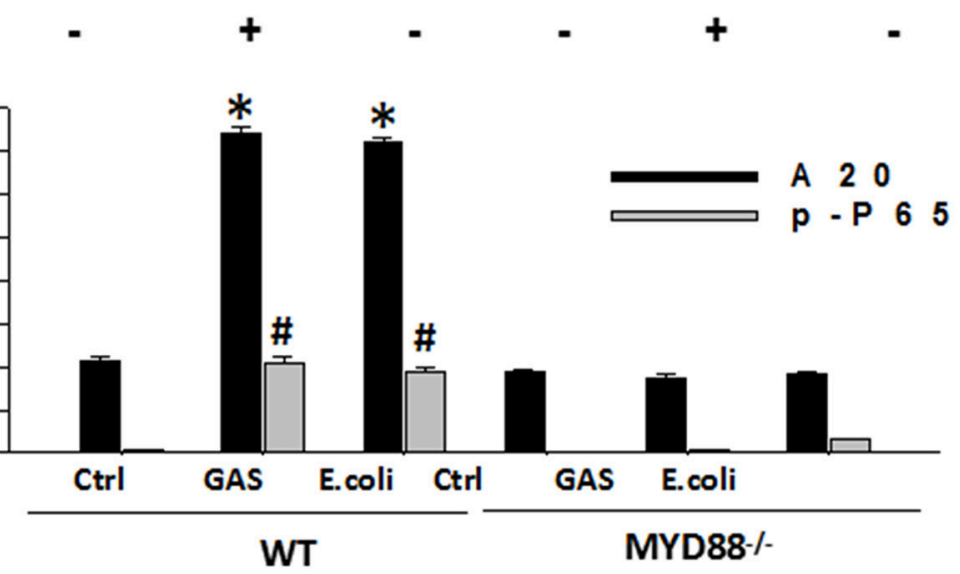

MYD88-\%-

FIGURE 6 | Western blot analysis of A20 expression in wild type or MyD88-/- BMDMs stimulated with GAS, and the detection of A20 expression following blockade with anti-TNFR1. BMDMs from MyD88 ${ }^{-1}$ knockout mice were stimulated with GAS at an MOI of 10. Six hours later, the treated cells were collected and determined by Western blotting using antibodies targeted to A20, p-P-65, and $\beta$-actin (A). ${ }^{*} P<0.05$ and $\# P<0.001$ vs. MyD88 ${ }^{-/-}$group. RAW cells were blocked with anti-TNFR1 monoclonal antibody for $30 \mathrm{~min}$ and then stimulated with GAS at an MOI of $10 \mathrm{for} 6 \mathrm{~h}$, following collection of the treated cells, A20 expression was detected by Western blotting (B). Each experiment was repeated three times, and similar results were obtained on each occasion. 
this in a mouse model infected with $1 \times 10^{7} \mathrm{CFU}$ of GAS or E. coli, or with PBS as a control for $48 \mathrm{~h}$, and then performed histopathological analysis using $H \& E$ staining and PAS staining. As expected, H\&E staining showed that the E. colichallenged lungs of mice contained abundant inflammatory cell infiltration in the alveolar walls, while PAS staining revealed intra-alveolar edema, and hemorrhage, accompanied by bronchiolitis with shed epithelium and mucus in the bronchus (Figures 2A,B). In contrast, GAS-challenged lungs showed a dramatic reduction of inflammatory cells along with reduced levels of mucus and alveolitis (Figures 2A,B). Lungs from the group of mice treated with $\mathrm{PBS}$ showed infiltration of only a few inflammatory cells and no mucus (Figures 2A,B). There were far fewer inflammatory cells in the BALF of the GAS group compared to the $E$. coli group $(P<0.0001)$, although, there was a significant difference between the GAS group and the PBS control $(P=0.0004$; Figure $2 \mathrm{C})$. These results indicated that when challenged with GAS, mice elicited a weaker inflammatory response compared with mice challenged with E. coli.

\section{A20 Expression Was Stronger and Lasted Longer in GAS-Stimulated RAW Cells and BMDM Than That of $E$. coli}

RAW cells were harvested following infection with GAS or E. coli (MOI of 10:1) at different time points, and the expression of A20 was analyzed by Western blotting. The results showed that A20 expression gradually increased in RAW cells from $2 \mathrm{~h}$ and peaked at $6-8 \mathrm{~h}$ following stimulation by GAS (Figure 3A). Accordingly, the expression of TRAF6, the down-stream target protein of A20, was reduced from 1 to $6 \mathrm{~h}$ and increased again from $8 \mathrm{~h}$. The expression of A20 in RAW cells stimulated by E. coli was delayed and was lower than that of cells stimulated by GAS. Accordingly,
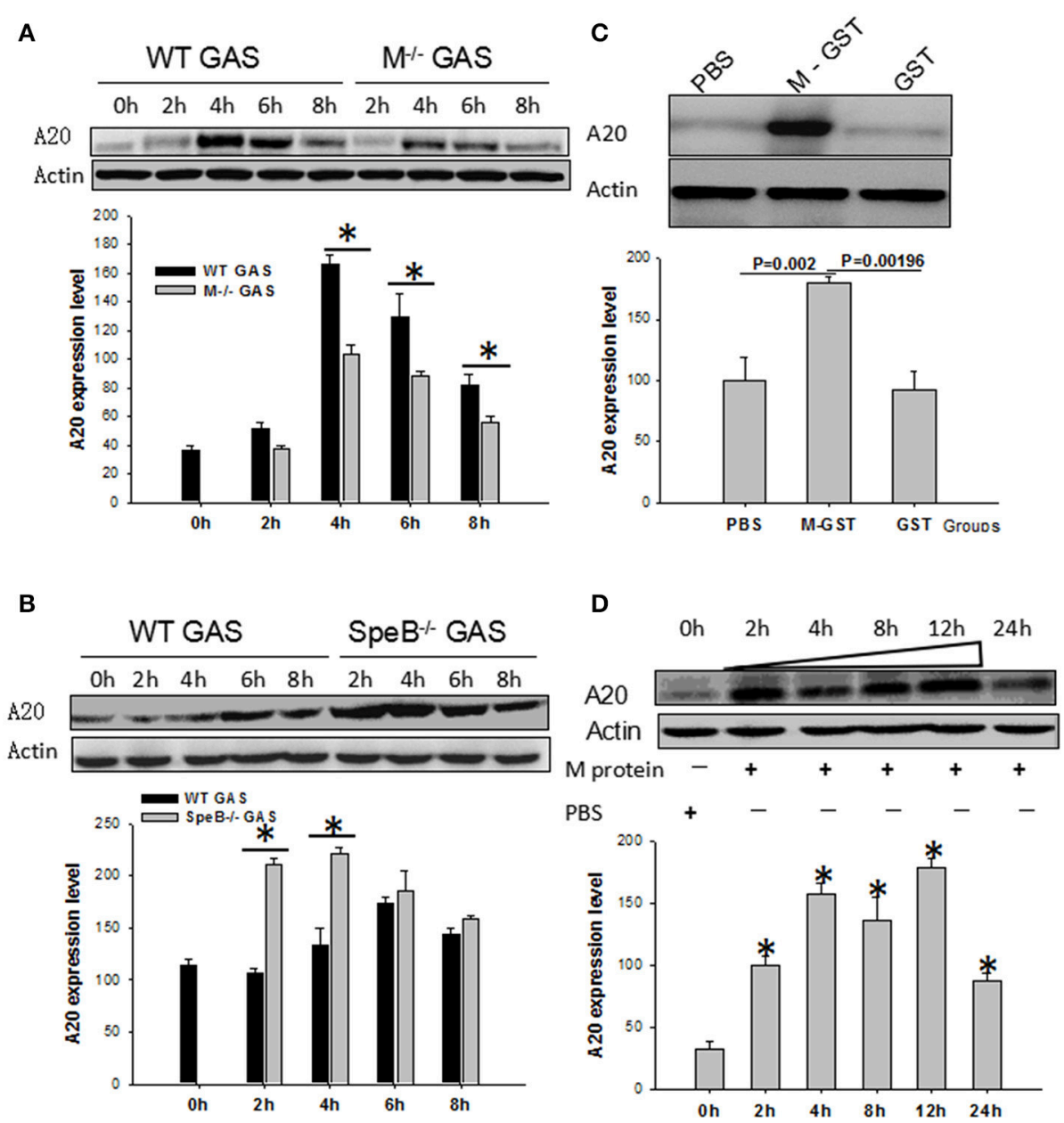

FIGURE 7 | WT RAW cells induced by gene mutant strain $\mathrm{M}^{-/-}$or SpeB ${ }^{-/-}$GAS, or WT GAS, or purified $\mathrm{M}$ protein. RAW cells were stimulated by WT or $\mathrm{M}^{-/-}$ (A) or SpeB ${ }^{-/-}$GAS (B) at an $\mathrm{MOI}$ of 10 . Six hours later, the treated cells were collected and A20 expression was determined by Western blotting. ${ }^{\star} P<0.05$ vs. the $\mathrm{M}^{-/-}$GAS group. RAW cells were stimulated by recombinant M-GST protein, GST-tag alone, and PBS as a control (C), or recombinant purified M protein and PBS as a control (D). Six hours later, the treated cells were collected and A20 expression was determined by Western blotting. Each experiment was repeated three times, and similar results were obtained on each occasion. 
TRAF6 expression fell from 2 to $4 \mathrm{~h}$ and then increased gradually from $6 \mathrm{~h}$. We also investigated these mechanisms in BMDM cells (Figure 3B) and observed a similar pattern of results. Consequently, the expression of A20 expression in GASinfected macrophages was higher and lasted longer than that of BMDM cells infected with E. coli; furthermore, the levels of TRAF6 were lower than those of BMDW cells infected with E. coli.

Next, we attempted to use an A20 SiRNA assay to confirm the above results. Following silencing of the A20 gene by SiA20 (Figures 4A,C), the level of TRAR6 clearly increased (Figure 4C). Correspondingly, p-P65 activation increased significantly (Figures 4B,C) in GAS-stimulated RAW cells for $6 \mathrm{~h}$. Simultaneously, the expression levels of IL-1 $\beta$, TNF- $\alpha$, and IL- 6 in the supernatant of GAS-stimulated RAW cells were all significantly enhanced compared with other groups (Figure 5). These results suggested that A20, a negative regulatory protein, is likely to play an essential role in inhibiting the expression of inflammatory factors in macrophages following GAS infection.

\section{GAS-Induced A20 Expression in Macrophages Mainly Depended on the MyD88-Signaling Pathway but Partially Depended on TNFR1}

In order to determine whether MyD88 was involved in the expression of A20, BMDM cells, harvested from MyD88 $8^{-/-}$knock-out mice, were infected with either GAS or $E$. coli for $6 \mathrm{~h}$ and then total cell protein was analyzed by Western blotting using WT BMDM cells as a control. As expected, the expression of A20 was much lower in MyD88 ${ }^{-/-}$ BMDM cells than in WT groups $(P<0.05)$; furthermore, we failed to detect the downstream protein $\mathrm{p}-\mathrm{P} 65$, in $\mathrm{MyD} 88^{-/-}$ BMDM cells stimulated by GAS (Figure 6A), suggesting that the expression of A20 is mainly dependent on the MyD88 signaling pathway in BMDM cells following GAS or E. coli infection.

Next, RAW cells were blocked with anti-TNFR1 monoclonal antibody prior to GAS infection. Data showed that A20 expression was slightly decreased when the dose of antiTNFR1 antibody was $10 \mu \mathrm{g} / \mathrm{ml}$ or less $(5 \mu \mathrm{g} / \mathrm{ml})$, and was even higher following blockage with a fold dose $(20 \mu \mathrm{g} / \mathrm{ml})$ than the negative control $(P<0.001)$, although significantly reduced expression was observed (Figure 6B), indicating that GAS-induced A20 expression is partially dependent on TNFR1.

\section{The M Protein of GAS Plays an Essential Role in the Induction of the A20 Gene}

Because, the $\mathrm{M}$ protein of GAS plays an important role in pathogenic mechanisms, we used qPCR and Western blotting to evaluate its role on the induction of the A20 gene in BMDM cells. Interestingly, we found that the expression of A20 induced by $\mathrm{M}^{-/-}$GAS was much lower than with WT GAS $(P<0.05$; Figure 7A). Streptococcal erythrogenic toxin B (SpeB), a cysteine protease, is capable of degrading $\mathrm{M}$ protein. Consequently, we investigated BMDM cells that had been infected with $\mathrm{SpeB}^{-/-}$GAS; Interestingly, A20 expression was vastly improved compared with WT GAS (Figure 7B), suggesting that the M protein might be related to GAS-induced A20 expression. To validate this supposition, we used M-GST protein to stimulate BMDM cells for $6 \mathrm{~h}$ to further test its function in terms of A20 gene induction, and found that M-GST induced higher A20 expression than the GST tag $(P<0.00196)$ or PBS control $(P<0.002$; Figure 7C). Subsequently, we removed the GST tag from the $\mathrm{M}$ protein, and then used it to stimulate BMDM cells, and measure A20 expression over different time points. Results showed that high levels of A20 expression appeared from 2 to $12 \mathrm{~h}$ (Figure $7 \mathrm{D}$ ), demonstrating that it is the $\mathrm{M}$ protein of GAS that plays an essential role in the expression of A20 by macrophages.

\section{DISCUSSION}

GAS is an important clinical pathogen that can cause a wide spectrum of diseases in humans, including pharyngitis, necrotizing fasciitis, erysipelas, toxic shock syndrome, sepsis, and even mortality. Furthermore, there is no effective prophylactic vaccine against GAS. Hence, it is very important to explore mechanisms underlying pathogenesis and resistance to immunity in order to identify novel therapeutic targets. The pathogenic effect of GAS is related to its strong toxicity and resistance to immunity (Horstmann et al., 1988), which is partially attributable to the GAS-mediated up-regulation of negative regulators in host cells. Host innate immune mechanisms play

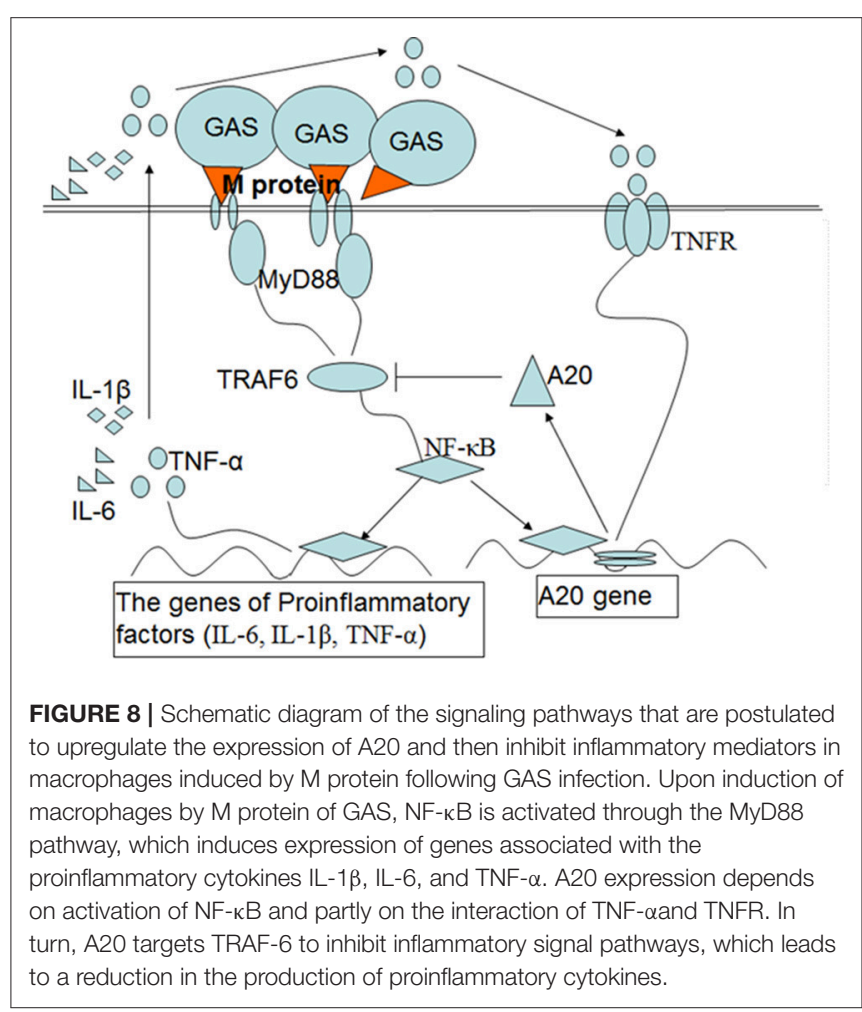


an essential role in controlling GAS growth and limiting the further spread of a pathogen beyond the site of infection (Goldmann et al., 2005). Resident macrophages have been shown to be critical in controlling infection in a mouse model (Goldmann et al., 2004). Generally, macrophages are activated by phagocytosis and express proinflammatory mediators such as TNF- $\alpha$, IL-1 $\beta$, and IL- 6 to recruit phagocytic cells, such as neutrophils, more macrophages, and dentritic cells, which, in turn, induce inflammation at local sites (Park et al., 2008; Netea et al., 2009; Rojas et al., 2010). Upon activation of macrophages by a pathogen, multiple signaling cascades are triggered, leading to activation of nuclear factor- $\kappa \mathrm{B}$ (NF$\kappa \mathrm{B})$ which induces the expression of genes associated with proinflammatory cytokines and chemokines (Topley et al., 1996). Considering that NF- $\mathrm{\kappa B}$ activation is central to many cellular processes and is closely-related to the expression of inflammatory cytokines, we analyzed NF- $\mathrm{kB}$ activation and the expression of proinflammatory mediators in macrophages infected with GAS. Surprisingly, results showed that compared with E. coli, GAS induced a lower expression level of inflammatory cytokines within $7 \mathrm{~h}$ of stimulation, and slight inflammation in the lung (Figure 2A). Accordingly, our previous results showed that the level of NF- $\kappa B$ activation induced by GAS was much lower than that by Staphylococcus aureus, but was similar to that induced by E. coli (Wu et al., 2016). It was not clear as to why the levels of inflammatory mediators induced by GAS were much lower than those induced by E. coli. However, we speculated that negative feedback proteins potentially played an essential role in the regulation of inflammatory mediators. To address this question, we investigated the expression of such negative factors, including SOCS-1 (Wu et al., 2015), SOCS3 , and A20. In particular, A20 is known to play a key role in the termination of NF- $\mathrm{KB}$ signaling, and inhibits activation of NF- $\mathrm{B}$ (Boone et al., 2004; Wertz et al., 2004). TNF receptor associated factor (TRAF) 6, which mediates interaction with the NF- $\mathrm{KB}$ essential modulator (NEMO), is a target protein for A20 and can be degraded by the deubiquitination of A20, resulting in the inhibition of NF- $\mathrm{KB}$ signals (Hitotsumatsu et al., 2008). The expression of A20 can be induced by various stimulators of inflammation, including bacterial endotoxins, exotoxins, and proinflammatory cytokines (TNF- $\alpha$ and IL1). In turn, $A 20$ can inhibit the excessive release of various inflammatory factors and adhesion molecules (Wertz et al., 2004; Liu et al., 2005). Our present results showed that the level of A20 expression induced by GAS was much higher than that induced by E. coli in RAW264.7 cells or BMDM,accordingly, the expression level of the target protein TRAF6 was lower than that induced by E. coli. Thus, the activation of NF- $\mathrm{KB}$ was obviously inhibited from 2 to $6 \mathrm{~h}$ after GAS stimulation, which led to a reduction in the expression of proinflammatory cytokines. To further demonstrate these points, we next performed A20 SiRNA analysis, which showed that the level of p-P65 was significantly increased (Figures 4B,C), importantly, both mRNA and protein levels of proinflammatory cytokines were also significantly increased after silencing of the A20 gene, as shown in Figure 5.
MyD88 is an important adaptor protein in inflammatory pathways and signaling pathways mediated by Toll-like receptors (TLRs). With the exception of TLR3, all TLRs are MyD88 dependent (Kawai and Akira, 2010). We infected MyD88 ${ }^{-/-}$ BMDMs with GAS to further investigate the correlation between MyD88 and A20, and found that there was no A20 expression in MyD88 knock-out cells, while A20 was detected readily in WT BMDM cells. This suggests that A20 expression is MyD88 dependent in both GAS- or E. coli-infected BMDM cells. However, there was no significant difference between the two groups in WT BMDM cells, indicating that MyD88 is not the main reason for differential A20 expression between the two groups.

In a previous study, Dixit et al. reported that binding of TNF- $\alpha$ to its receptor TNFR1 is the main signaling pathway mediating A20 expression after cytokine synthesis (Dixit et al., 1990; Opipari et al., 1992). In the present study, we detected high expression of TNF- $\alpha$ in GAS-induced macrophages. However, the blockade of RAW cells with anti-TNFR1 antibody showed that the expression of A20 was only partially blocked in GASinfected RAW cells, indicating that the expression of A20 was partially dependent on the TNFR1 pathway. Consequently, we analyzed some important surface proteins of GAS in order to evaluate whether they had an effect on A20 expression. M protein and streptococcal erythrogenic toxin B (SpeB) of GAS were included in this analysis, largely because $M$ protein is the most important membrane protein and the key virulence factor of GAS (Lancefield, 1962). This protein can exhibit a strong proinflammatory effect and contributes to the way in which GAS can evade phagocytosis via macrophages (Ma et al., 2009; Metzgar and Zampolli, 2011). SpeB is a cysteine protease known to cleave $\mathrm{M}$ protein from GAS (Raeder et al., 1998; Chaussee et al., 2000; Wei et al., 2005), while M protein affects the maturation of SepB. Interestingly, we found that A20 expression induced by $\mathrm{M}^{-/-}$GAS was significantly decreased compared with that induced by WT GAS. Instead, $\mathrm{SpeB}^{-}$GAS induced A20 expression was much higher than that of WT GAS in BMDM cells (Figures 7A,B), suggesting that when the SpeB gene of GAS was knocked out, the stability of the M protein was enhanced, thus leading to a higher level of A20 expression than that induced by WT GAS. This theory was proven by using purified $\mathrm{M}$ protein to stimulate macrophages (Figures 7C,D).

In summary, GAS induces a high level of A20 expression through its surface $\mathrm{M}$ protein which inhibits the inflammatory signal pathways, thus leading to a decrease in the production of proinflammatory cytokines (Figure 8). Thus, fewer inflammatory cells were recruited to the local infection site, which, in turn, might be conducive to GAS growth and further spread of the pathogen beyond the site of infection. In a previous paper, Liu et al. reported that the E3 ubiquitin ligase, TRIM29, inhibited interferon-regulatory factors and signaling via the transcription factor NF-kB of alveolar macrophages following infection with virus such as influenza virus (Xing et al., 2016). Collectively, our data and other studies implied that the function of macrophage could be regulated by several regulatory factors 
when infected by pathogens. This may have essential implications for our understanding of pathogenesis, as well as interactions between the host and the pathogen.

\section{AUTHOR CONTRIBUTIONS}

LW and CM conceived and designed the experiments. CM, $\mathrm{XG}$, and SW performed the experiments. LZ, JW, ZZ, ZY, and $\mathrm{XS}$ analyzed the data. WL, XW, and HF contributed reagents,

\section{REFERENCES}

Boone, D. L., Turer, E. E., Lee, E. G., Ahmad, R. C., Wheeler, M. T., Tsui, C., et al. (2004). The ubiquitin-modifying enzyme A20 is required for termination of Toll-like receptor responses. Nat. Immunol. 5, 1052-1060. doi: 10.1038/ ni1110

Bradford, M. M. (1976). A rapid and sensitive method for the quantitation of microgram quantities of protein utilizing the principle of protein-dye binding. Anal. Biochem. 72, 248-254. doi: 10.1016/0003-2697(76)90527-3

Bryant, A. E., Hayes-Schroer, S. M., and Stevens, D. L. (2003). M type 1 and 3 group A streptococci stimulate tissue factor-mediated procoagulant activity in human monocytes and endothelial cells. Infect. Immun. 71, 1903-1910. doi: 10.1128/IAI.71.4.1903-1910.2003

Chaussee, M. S., Cole, R. L., and Putten, J. P. M. V. (2000). Streptococcal erythrogenic toxin B abrogates fibronectin-dependent internalization of Streptococcus pyogenes by cultured mammalian cells. Infect. Immun. 68, 3226-3232. doi: 10.1128/IAI.68.6.3226-3232.2000

Collin, M., and Olsén, A. (2002). Generation of a mature streptococcal cysteine proteinase is dependent on cell wall-anchored M1 protein: maturation of streptococcal cysteine proteinase. Mol. Microbiol. 36, 1306-1318. doi: 10.1046/j.1365-2958.2000.01942.x

Collin, M., Svensson, M. D., Sjöholm, A. G., Jensenius, J. C., Sjöbring, U., and Olsén, A. (2002). EndoS and SpeB from Streptococcus pyogenes inhibit immunoglobulin-mediated opsonophagocytosis. Infect. Immun. 70, 6646-6651. doi: 10.1128/IAI.70.12.6646-6651.2002

Cue, D., Dombek, P. E., Lam, H., and Cleary, P. P. (1998). Streptococcus pyogenes serotype M1 encodes multiple pathways for entry into human epithelial cells. Infect. Immun. 66, 4593-4601.

Cunningham, M. W. (2000). Pathogenesis of group A streptococcal infections. Clin. Microbiol. Rev. 13:470. doi: 10.1128/CMR.13.3.470-511.2000

Dixit, V. M., Green, S., Sarma, V., Holzman, L. B., Wolf, F. W., O’Rourke, K., et al. (1990). Tumor necrosis factor-alpha induction of novel gene products in human endothelial cells including a macrophage-specific chemotaxin. J. Biol. Chem. 265, 2973-2978.

Goldmann, O., Lengeling, A., Böse, J., Bloecker, H., Geffers, R., Chhatwal, G. S., et al. (2005). The role of the MHC on resistance to group a streptococci in mice. J. Immunol. 175, 3862-3872. doi: 10.4049/jimmunol.175.6.3862

Goldmann, O., Rohde, M., Chhatwal, G. S., and Medina, E. (2004). Role of macrophages in host resistance to group A streptococci. Infect. Immun. 72, 2956-2963. doi: 10.1128/IAI.72.5.2956-2963.2004

Hitotsumatsu, O., Ahmad, R. C., Tavares, R., Min, W., Philpott, D., Turer, E. E., et al. (2008). The ubiquitin-editing enzyme A20 restricts nucleotide-binding oligomerization domain containing 2-triggered signals. Immunity 28, 381-390. doi: 10.1016/j.immuni.2008.02.002

Horstmann, R. D., Sievertsen, H. J., Knobloch, J., and Fischetti, V. A. (1988). Antiphagocytic activity of streptococcal M protein: selective binding of complement control protein factor H. Proc. Natl. Acad. Sci. U.S.A. 85, 1657-1661. doi: 10.1073/pnas.85.5.1657

Kawai, T., and Akira, S. (2010). The role of pattern-recognition receptors in innate immunity: update on Toll-like receptors. Nat. Immunol. 11, 373-384. doi: $10.1038 /$ ni.1863

Kubista, M., Andrade, J. M., Bengtsson, M., Forootan, A., Jonák, J., Lind, K., et al. (2006). The real-time polymerase chain reaction. Mol. Aspects Med. 27:95. doi: 10.1016/j.mam.2005.12.007 materials, analysis tools. CM and XG wrote the manuscript. All authors read and approved the final version of the manuscript.

\section{FUNDING}

The work was supported by grants from the National Natural Science Foundation of China (grants 31370914, 30901350, and 81172810) and the Natural Science Foundation of Hebei Province (H2016206516).
Lancefield, R. C. (1962). Current knowledge of type-specific M antigens of group A streptococci. J. Immunol. 89, 307-313.

Liang, Y., Liu, X., Chang, H., Ji, L., Huang, G., Fu, Z., et al. (2012). Epidemiological and molecular characteristics of clinical isolates of Streptococcus pyogenes collected between 2005 and 2008 from Chinese children. J. Med. Microbiol. 61(Pt 7), 975-983. doi: 10.1099/jmm.0.042309-0

Liu, Y. C., Penninger, J., and Karin, M. (2005). Immunity by ubiquitylation: a reversible process of modification. Nat. Rev. Immunol. 5, 941-952. doi: 10.1038/nri1731

Ma, C., Guo, Y., Gu, H., Zhang, L., Liu, H., Feng, H., et al. (2011). A novel monoclonal antibody against FbaA can inhibit the binding of the complement regulatory protein factor $\mathrm{H}$ to group A streptococcus. Clin. Vaccine Immunol. 18, 552-558. doi: 10.1128/CVI.00438-10

Ma, C. Q., Li, C. H., Wang, X. R., Zeng, R. H., Yin, X. L., Feng, H. D., et al. (2009). Similar ability of FbaA with M protein to elicit protective immunity against group A streptococcus challenge in mice. Cell. Mol. Immunol. 6, 73-77. doi: $10.1038 / \mathrm{cmi} .2009 .10$

Metzgar, D., and Zampolli, A. (2011). The M protein of group A Streptococcus is a key virulence factor and a clinically relevant strain identification marker. Virulence 2, 402-412. doi: 10.4161/viru.2.5.16342

Netea, M. G., Nold-Petry, C., Nold, M. F., Joosten, L. A., Opitz, B., Van-Der-Meer, J., et al. (2009). Differential requirement for the activation of the inflammasome for processing and release of IL-1beta in monocytes and macrophages. Blood 113, 2324-2335. doi: 10.1182/blood-2008-03-146720

Opipari, A. W., Hu, H. M., Yabkowitz, R., and Dixit, V. M. (1992). The A20 zinc finger protein protects cells from tumor necrosis factor cytotoxicity. J. Biol. Chem. 267, 12424-12427.

Pandiripally, V., Wei, L., Skerka, C., Zipfel, P. F., and Cue, D. (2003). Recruitment of complement factor H-like protein 1 promotes intracellular invasion by group A streptococci. Infect. Immun. 71, 7119-7128. doi: 10.1128/IAI.71.12.7119-7128.2003

Park, P. H., Huang, H., McMullen, M. R., Mandal, P., Sun, L., and Nagy, L. E. (2008). Suppression of lipopolysaccharide-stimulated tumor necrosis factor- $\alpha$ production by adiponectin is mediated by transcriptional and post-transcriptional mechanisms *. J. Biol. Chem. 283, 26850-26858. doi: 10.1074/jbc.M802787200

Raeder, R., Woischnik, M., Podbielski, A., and Boyle, M. D. P. (1998). A secreted streptococcal cysteine protease can cleave a surface-expressed M1 protein and alter the immunoglobulin binding properties. Res. Microbiol. 149, 539-548. doi: 10.1016/S0923-2508(99)80001-1

Rojas, M., Zhang, W., Lee, D. L., Romero, M. J., Nguyen, D. T., AlShabrawey, M., et al. (2010). Role of IL-6 in angiotensin II-induced retinal vascular inflammation. Invest. Ophthalmol. Vis. Sci. 51, 1709-1718. doi: 10.1167/iovs.09-3375

Terao, Y., Kawabata, S., Kunitomo, E., Murakami, J., Nakagawa, I., and Hamada, S. (2001). Fba, a novel fibronectin-binding protein from Streptococcus pyogenes, promotes bacterial entry into epithelial cells, and the fba gene is positively transcribed under the Mga regulator. Mol. Microbiol. 42, 75-86. doi: 10.1046/j.1365-2958.2001.02579.x

Topley, N., Liberek, T., Davenport, A., Li, F.-K., Fear, H., and Williams, J. D. (1996). Activation of inflammation and leukocyte recruitment into the peritoneal cavity. Kidney Int. Suppl. 56, S17-S21.

Wei, L., Pandiripally, V., Gregory, E., Clymer, M., and Cue, D. (2005). Impact of the SpeB protease on binding of the complement regulatory proteins factor $\mathrm{H}$ and 
factor H-like protein 1 by Streptococcus pyogenes. Infect. Immun. 73, 2040-2050. doi: 10.1128/IAI.73.4.2040-2050.2005

Wertz, I. E., O’Rourke, K. M., Zhou, H., Eby, M., Aravind, L., Seshagiri, S., et al. (2004). De-ubiquitination and ubiquitin ligase domains of A20 downregulate NF-B signalling. Nature. 430, 694-699. doi: 10.1038/nature 02794

Wu, J., Ma, C., Wang, H., Wu, S., Xue, G., Shi, X., et al. (2015). A MyD88JAK1-STAT1 complex directly induces SOCS-1 expression in macrophages infected with Group A Streptococcus. Cell. Mol. Immunol. 12, 373-383. doi: $10.1038 / \mathrm{cmi} .2014 .107$

Wu, S., Ma, C., Gao, X., Zhang, L., Miao, Q., Li, M., et al. (2016). Group A Streptococcus induced less P65 nuclear translocation and nonclassical NF- $\kappa$ B activation in macrophage, which possibly leads to a weaker inflammatory response. Int. J. Infect. Dis. 44, 50-60. doi: 10.1016/j.ijid.2016. 01.018
Xing, J., Weng, L., Yuan, B., Zhuo, W., Li, J., Rui, J., et al. (2016). Identification of a role for TRIM29 in the control of innate immunity in the respiratory tract. Nat. Immunol. 17, 1373-1380. doi: 10.1038/ni.3580

Conflict of Interest Statement: The authors declare that the research was conducted in the absence of any commercial or financial relationships that could be construed as a potential conflict of interest.

Copyright $\odot 2018$ Ma, Gao, Wu, Zhang, Wang, Zhang, Yao, Song, Li, Wang, Feng and Wei. This is an open-access article distributed under the terms of the Creative Commons Attribution License (CC BY). The use, distribution or reproduction in other forums is permitted, provided the original author(s) and the copyright owner are credited and that the original publication in this journal is cited, in accordance with accepted academic practice. No use, distribution or reproduction is permitted which does not comply with these terms. 